\title{
Cachexia in Cancer Patients: Systematic Literature Review
}

\author{
Timotius I. Hariyanto ${ }^{1}$ Andree Kurniawan² \\ ${ }^{1}$ Faculty of Medicine, Pelita Harapan University, Boulevard Jendral \\ Sudirman Street, Karawaci, Tangerang, Banten, Indonesia \\ ${ }^{2}$ Department of Internal Medicine, Faculty of Medicine, Pelita \\ Harapan University, Boulevard Jendral Sudirman Street, Karawaci, \\ Tangerang, Banten, Indonesia
}

\begin{abstract}
Address for correspondence Timotius I. Hariyanto, MD, Faculty of Medicine, Pelita Harapan University, Boulevard Jendral Sudirman Street, Karawaci, Tangerang, Banten 15811, Indonesia (e-mail: timotius.hariyanto95@gmail.com).
\end{abstract}

\begin{abstract}
Introduction Cachexia in cancer patients, especially in advanced stage, is recently known as an emerging problem. Cachexia occurs in about half of all patients with neoplastic disease. The diagnosis of cachexia needs comprehensive evaluation of body weight and body composition for several months. Cachexia will give negative impacts such as increased mortality, chemotoxicity, and decreased quality of life. Here, we review the current evidence describing the definition, stages, mechanisms, diagnosis and treatment of cachexia in cancer patients.

Methods We identified 75 studies and/or review articles evaluating cachexia and weight loss in cancer patients by searching PubMed and EMBASE databases.

Results Cachexia is reported across all stages and types of cancers. The most recent definition of cachexia is reported in a 2011 paper by International Consensus. The mechanism of cachexia in cancer is complex and involved many factors which elaborate together to produce cachexia. The diagnostic evaluation and cut-off measurement of cachexia, especially in cancer varied across studies. The loss of weight that happens during chemotherapy will make a poor prognosis. Cachexia can worsen chemotherapy toxicity. Combination of dietary modification and exercise with supplementation of medication that control appetite and inflammation are important in the management of cachexia in cancer patients.

Keywords

- cachexia

- weight loss

- cancer

Conclusion Patients with cancer are the population at risk for developing cachexia before and after chemotherapy. Cachexia diagnosis needs evaluation of body weight and body composition. Nonpharmacological treatments, such as dietary modification and physical exercise, are the best strategy to reduce cachexia in cancer patients.
\end{abstract}

\section{Introduction}

Cachexia is a disorder characterized by the involuntary loss of body weight in addition to loss of homeostatic control of both energy and protein balance. ${ }^{1}$ Cachexia is associated with several chronic diseases and in particular, it can be observed as a paraneoplastic syndrome inpatients affected by cancer. Cachexia pathophysiology is associated with systemic inflammation that involved many cytokines and mediators, negative protein and energy balance, and an involuntary loss of lean body mass with lipolysis. ${ }^{2}$ Cachexia can have a profound impact on quality of life (QOL), symptom burden, and a patient's sense of dignity. It is a very serious complication, as weight loss during cancer treatment is associated with more chemotherapy-related side effects, fewer completed cycles of chemotherapy, and decreased survivalrates. ${ }^{3}$ Cancer cachexia, at least in a mild form, occurs in approximately $50 \%$ of all patients with neoplastic disease and is a poor prognosticator. ${ }^{4}$ Importantly, more than $20 \%$ of patients with diagnosis of cancer will die due to cancer cachexia. ${ }^{5,6}$
DOI https://doi.org/

10.1055/s-0040-1713701

ISSN 2454-6798.
License terms

(1) (1) $\odot \circledast$ 
Current therapies focus on palliation of symptoms and the reduction of distress of patients and families rather than cure. ${ }^{7}$ By combining pharmacological and nonpharmacological interventions, the multifaceted mechanisms of this complex syndrome could be addressed simultaneously, resulting in improved protein and caloric intake, gains in muscle and fat, and better physical function.

\section{Search Strategies}

A comprehensive search of literature was conducted in the PubMed (National Institute of Health [NIH]) and EMBASE database (March 1962-March 2019) using keyword combinations of the medical subject headings (MeSH) of "cachexia," "weight loss," "anorexia," "body composition," "muscle wasting," "energy balance," "malnutrition," "cancer," and "neoplasm." Relevant reference lists were also manually searched.

\section{Definition of Cachexia}

Cachexia is defined as a complex metabolic syndrome associated with underlying illness and characterized by loss of muscle mass with or without loss of fat mass. ${ }^{8}$ Cachexia itself has been known for centuries. Cachexia was first described by Hippocrates as "the flesh is consumed and becomes water... the abdomen fills with water, the feet and legs swell, the shoulders, clavicles, chest, and thighs melt away... The illness is fatal." ${ }^{\prime \prime}$ The term cachexia is derived from the Greek words kakós, meaning "bad things," and hexis, meaning "condition or appearance."10

A consensus meeting was recently held to define cachexia, finally reaching a clinical definition that can be applied in almost any clinical entity. It was eventually published in 2008. The definition that emerged is: "cachexia is a complex metabolic syndrome associated with underlying illness and characterized by loss of muscle with or without loss of fat mass." The prominent clinical feature of cachexia is weight loss in adults (corrected for fluid retention) or growth failure in children (excluding endocrine disorders). Anorexia, inflammation, insulin resistance and increased muscle protein breakdown are frequently associated with wasting disease. Wasting disease is distinct from starvation, age-related loss of muscle mass, primary depression, malabsorption and hyperthyroidism and is associated with increased morbidity. ${ }^{11}$

The consensus panel developed a set of diagnostic criteria to allow clinicians and researchers to make a definitive diagnosis of cachexia (-Table $\mathbf{1}) \cdot{ }^{11}$ The key component was at least a $5 \%$ loss of edema-free bodyweight during the previous 12 months or less. The timeframe may be disease specific and is likely to be shorter in cancer (3-6 months) and longer in chronic kidney or heart failure or chronic obstructive pulmonary disease (COPD; 12 months). In cases where a history of weight loss cannot be documented, a body mass index (BMI) of $<20.0 \mathrm{~kg} / \mathrm{m}^{2}$ was considered sufficient to establish a diagnosis of cachexia. ${ }^{11}$

In 2011, an international group of experts provided the following definition of cancer cachexia: "a multifactorial
Table 1 Diagnostic criteria for cachexia in adults ${ }^{11}$

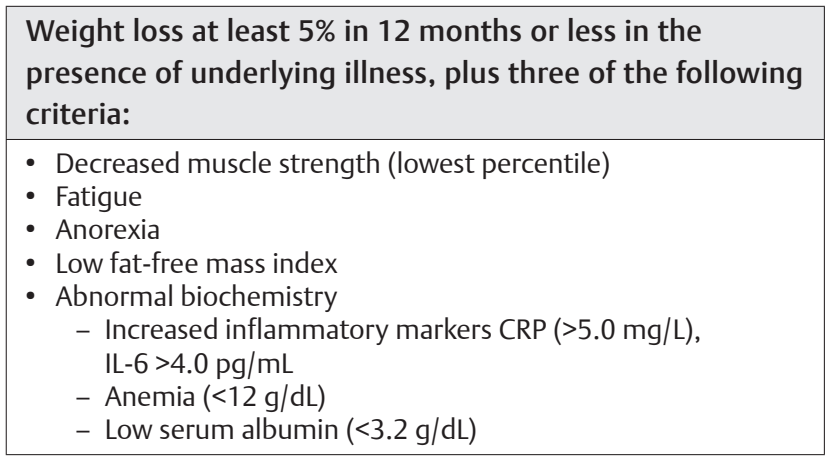

Abbreviation: CRP, C-reactive protein.

Table 2 Operational diagnostic criteria for cancer cachexia ${ }^{12}$

- Weight loss $>5 \%$ over past 6 months (in absence of simple
starvation)
- $\mathrm{BMI}<20 \mathrm{~kg} / \mathrm{m}^{2}$ and any degree of weight loss $>2 \%$
- Appendicular skeletal muscle index consistent with
sarcopenia and any degree of weight loss $>2 \%$

syndrome defined by an ongoing loss of skeletal muscle mass (with or without loss of fat mass) that can be partially but not entirely reversed by conventional nutritional support." ${ }^{12}$ This definition highlighted the loss of skeletal muscle mass associated with cancer cachexia and its complications including increased chemotherapy toxicity and mortality. They also offer new diagnostic criteria for cachexia in cancer patients $\left(\right.$ - Table 2). ${ }^{12}$

\section{Stages of Cachexia in Cancer}

Cancer cachexia is a continuum (with three stages of clinical relevance: pre-cachexia, cachexia, and refractory cachexia. Not all patients traverse the entire spectrum. In precachexia, early clinical and metabolic signs (e.g., anorexia and impaired glucose tolerance) can precede substantial involuntary weight loss (i.e., $\leq 5 \%$ ). ${ }^{12}$ The risk of progression varies and depends on factors such as cancer type and stage, the presence of systemic inflammation, low food intake, and lack of response to anticancer therapy. Patients who have more than 5\% loss of stable body weight over the past 6 months, or a BMI $<20 \mathrm{~kg} / \mathrm{m}^{2}$ and ongoing weight loss of more than $2 \%$, or sarcopenia and ongoing weight loss of more than $2 \%$, but have not entered the refractory stage, are classified as having cachexia. ${ }^{12}$ In refractory cachexia, the cachexia can be clinically refractory as a result of very advanced cancer (preterminal) or the presence of rapidly progressive cancer unresponsive to anticancer therapy. ${ }^{12}$ This stage is associated with active catabolism, or the presence of factors that render active management of weight-loss no longer possible or appropriate. Refractory cachexia is characterized by a low performance status (World Health Organization [WHO] score 3 or 4 ) and a life expectancy of less than 3 months. ${ }^{12}$ 
A preliminary study in cancer patients supported the proposed three-level staging system with respect to symptom burden, QOL, tolerability for chemotherapy, and mortality; however, patients in the precachectic and cachexia group behaved in a similar manner. ${ }^{13}$

Argilés et al developed a scoring system called cachexia score (CASCO) to enable proper quantitative staging of cachectic cancer patients. ${ }^{14}$ CASCO is mainly based on the following constituents: (1) body weight loss and composition, (2) inflammation/metabolic disturbances/immunosuppression, (3) physical performance, (4) anorexia, and (5) QOL. The score ranges from 0 to 100 , mild cachexia $(<25)$, moderate ( $>26$ and $<50)$, severe ( $>51$ and $<75$ ), and terminal phase (>76 and up to 100). This scoring system has been validated and can be used in many cancer types with a clear advantage over previous classifications. ${ }^{14}$

\section{Mechanism of Cachexia in Cancer}

Cachexia is characterized by a combination of events. There is a negative protein and energy balance driven by a combination of reduced food intake and abnormal metabolism. There are several proposed mechanism of cancer cachexia (-Fig. 1).

\section{Cytokines, Inflammation, and Hypermetabolic State}

Increases in resting energy expenditure (REE; also called basal metabolic rate) may contribute to the energy deficits that lead to wasting. An increase in REE, as measured by indirect calorimetry, has been observed in patients with lung cancer ${ }^{15}$ and sarcomas, ${ }^{16}$ and it is thought to contribute to the weight loss observed in cancer cachexia.

Numerous cytokines, including tumor necrosis factor- $\alpha$ (TNF- $\alpha$ ), interleukin-1 (IL-1), IL-6, and interferon-gamma (IFN- $\gamma$ ) have been postulated to play a role in the etiology of cancer cachexia. ${ }^{17-19}$ Cytokines activate nuclear transcription factor $\mathrm{\kappa B}(\mathrm{NF}-\mathrm{KB})$ that results in decreased muscle protein synthesis. ${ }^{20}$ Cytokine activation is also responsible for the reduction of MyoD protein, a transcription factor that modulates signaling pathways involved in muscle development, resulting in muscle wasting. ${ }^{21}$

\section{Lipolysis and Lipid-Mobilizing Factor}

Although wasting of lean body mass is a major aspect of cancer cachexia, loss of fat mass also occurs. A tumor-produced lipid-mobilizing factor (LMF) may contribute to wasting of fat tissue. ${ }^{22}$ It is postulated that LMF acts to sensitize adipose tissue to lipolytic stimuli by increasing cyclic adenosine monophosphate (AMP) production in adipocytes. ${ }^{23}$ This effect may be mediated through the $\beta$-adrenergic receptor, with increased receptor number or G-protein expression. ${ }^{22,23}$

\section{The ATP-Ubiquitin-Proteasome Pathway}

Activation of the adenosine triphosphate (ATP)-ubiquitinproteasome pathway may play an important role in cancer-associated tissue wasting as illustrated by two experimental study on animal found that free ubiquitin and ubiquitin conjugates were higher in gastrocnemius muscle of tumor-implanted rats than in muscles from control rats ${ }^{24}$ and that inhibition of the ubiquitin-proteasome pathway with the proteasome inhibitor MG132 can ameliorate cachexia in tumor-bearing mice. ${ }^{25}$ Thus, the ubiquitin-proteasome pathway may be the final common pathway mediating protein degradation in cachexia.

\section{Reduced Dietary Intake or Absorption}

Anorexia and poor oral intake contribute to the energy deficits observed in cancer cachexia. Hormones and mediators, like leptin and serotonin (5-HT), may play role in the development of cancer-induced anorexia. ${ }^{26,27}$ Leptin reduces appetite and increases energy expenditure via central nervous system. ${ }^{26}$ Thus, if a disease processes, such as cancer was to produce factors that induce or mimic the hypothalamic effect of excess negative feedback signaling from leptin, the expected outcome would be sustained anorexia (lack of appetite) and cachexia (muscle wasting and uncontrolled weight loss), without the usual compensatory response. ${ }^{28}$ Increased level of plasma and brain tryptophan, the precursor of 5-HT, and IL-1 may underlie the increased serotonergic activity seen in the cancer cachexia. The 5-HT activates various serotonin receptor subtypes in the gastrointestinal tract and ganglia, exerting a range of biological and physiological effects, such as nausea and vomiting, which can induces anorexia. ${ }^{29}$

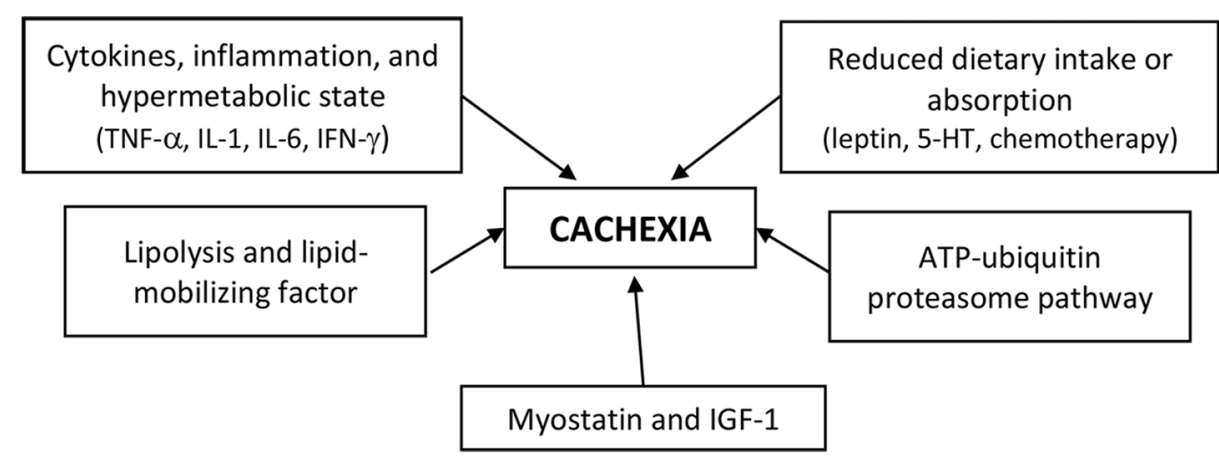

Fig. 1 Pathophysiology of cancer induced cachexia. ${ }^{18,22,24,26,30,31,34} 5-\mathrm{HT}$, leptin and serotonin; ATP, adenosine triphosphate; IFN, interferon-gamma; IGF-1, insulin-like growth factor-1; IL, interleukin; TNF, tumor necrosis factor. 
Chemotherapy-related alterations in taste and smell may also contribute to this loss of apetite. ${ }^{30}$

\section{Myostatin and Insulin-Like Growth Factor-I}

Myostatin is an extracellular cytokine that is mostly expressed in skeletal muscles and is known to play a crucial role in the negative regulation of muscle mass. ${ }^{31}$ Upon binding to the activating type-IIB receptor, myostatin can initiate several different signaling cascades, resulting in decreased muscle growth and differentiation. ${ }^{31}$ Transgenic mice with the myostatin gene develop a cachexia-like syndrome that manifests with severe wasting. ${ }^{32}$ On the other side, insulin-like growth factor-I (IGF-1) is highly sensitive to food intake. Under normal conditions, IGF-1 signaling seems to be dominant and blocks the myostatin pathway. However, an inhibition of IGF-1 can occur when myostatin is overexpressed..$^{33}$ It was shown that in the absence of IGF-1, the level of apoptosis in $\mathrm{C} 2 \mathrm{C} 12$ cells treated with myostatin increased, ${ }^{31}$ and the levels of IGF-1 is reduced in experimental models of cachexia. ${ }^{34}$

\section{Impact of Cachexia on Cancer}

Cachexia has marked effects on QOL, physical function, and mortality in cancer patients when compared with weightstable patients. One reason for these effects may be related to the increased toxicity related to cancer-directed treatments with body composition changes. ${ }^{35}$ Drug doses are typically administered on the basis of body surface area, which does not account for muscle loss (i.e., sarcopenia, cachexia), fat gain, or water retention. ${ }^{36}$ Consequently, the volume of distribution of cancer treatments can be impacted not only from a change in lean body mass, but also from changes in fat mass and total body water. This change in volume of distribution may decrease the effectiveness and/or increase toxicities of cancer directed therapies. Body composition changes as a predictor of toxicity have been documented in breast, lung, esophageal, and colon cancers. ${ }^{37}$

Cachexia negatively impacts on surgical risk and response to chemotherapy and radiotherapy and ultimately results in decreased QOL. ${ }^{3}$ Cancer patients experiencing weight loss leading up to and during chemotherapy receive a lower initial dose and experience more frequent and severe dose-limiting toxicity when compared with weight-stable patients, ${ }^{35,37}$ consequently receiving significantly less treatment. These patients also experienced decreased QOL, performance status and survival intervals and lowered response to treatment.

\section{Screening of Cancer Cachexia}

Cachexia screening is performed with the aim of increasing awareness and enabling early recognition and treatment. To detect cachexia at an early stage and to detect its acceleration, regular evaluation of weight change and BMI are needed, beginning at cancer diagnosis and repeated depending on the stability of the clinical situation. Mandatory screening for weight loss in patients with cancer has been established in some countries, ${ }^{38}$ with the intent of detecting in-hospital malnutrition.

Until now, there are no common assessment tools or validated measurements for screening of cachexia in cancer patients. Due to the lack of a specific cachexia assessment tool, malnutrition assessment tools are used in daily practice (-Table 3) ${ }^{39}$ The most commonly used malnutrition assessment tools are patient-generated subjective global assessment (PG-SGA), ${ }^{40}$ mini-nutritional assessment (MNA), ${ }^{41}$ malnutrition-screening tool (MST), ${ }^{42}$ malnutrition universal screening tool (MUST), ${ }^{43}$ and nutritional risk screening-2002 (NRS-2002). ${ }^{44}$ The current malnutrition assessment tools are helpful to screen for malnutrition in health care and these tools are utilized to recommend nutritional support but they do not guide multimodal cachexia therapy. The malnutrition assessment tools only marginally assess the impact of cachexia, whether physical or psychosocial. Some of the instruments include performance status, others ask about depression, but functional impairment caused by cachexia and eating-related distress is not part of the established tools. $^{39}$

\section{Diagnosis of Cachexia in Cancer Patient}

In the daily routine, very often the diagnosis of cachexia in cancer patients is made on the basis of a reduced food intake. Because of the complex condition of cancer patients, this could be misleading because the reduction of ingested

Table 3 Cachexia assessment domains covered by malnutrition assessment tools ${ }^{39}$

\begin{tabular}{|l|l|l|l|l|l|}
\hline & PG-SGA & MNA & MST & MUST & NRS 02 \\
\hline Stores depletion & $\mathrm{x}$ & $\mathrm{x}$ & $\mathrm{x}$ & $\mathrm{x}$ & $\mathrm{x}$ \\
\hline Muscle mass and strength & $\mathrm{x})^{\mathrm{a}}$ & $\mathrm{x}^{\mathrm{b}}$ & $\mathrm{x}$ & $\mathrm{x}$ & $\mathrm{x}$ \\
\hline Anorexia or reduced food intake & $\mathrm{x}$ & $\mathrm{x}$ & & \\
\hline Catabolic drivers & $(\mathrm{x})^{\mathrm{c}}$ & & & \\
\hline Functional and psychological effects & $\mathrm{x}$ & $\mathrm{x}$ & & \\
\hline
\end{tabular}

Abbreviations: MNA, mini-nutritional assessment; MST, malnutrition-screening tool; MUST, malnutrition universal screening tool; NRS, nutritional risk screening; PG-SGA, patient-generated subjective global assessment.

anly physical examination.

bOnly calf circumference.

'Only fever and corticosteroids. 
calories might be the consequence of dysphagia or depression rather than a sign of cachexia. The diagnosis of CACS is complex and requires therefore a meticulous clinical examination of the patient ( - Table 4 ). ${ }^{45}$

\section{Assessment of Weight Loss}

The presence of weight loss is an important clinical sign that can even be the first detectable manifestation of the presence of cancer and can be easily obtained by patients and caregivers or measured by health care providers ${ }^{45}$ After the possibility of intentional weight loss (for example, by dieting) has been excluded, alternative causes of weight loss of unknown origin are investigated. Weight loss is typically the first element of a cachexia diagnosis, so the presence of unintentional weight loss of more than $5 \%$ of premorbid weight in a 6 months period should be assessed. ${ }^{12,46}$ Weight loss varies in its severity: a $5 \%$ loss is considered the threshold of major risk of poor clinical outcome, ${ }^{4,12}$ with increasing risk as weight loss cumulatively reaches $10,15,20 \%$. or higher. ${ }^{47}$

\section{Assessment of Body Composition}

One of the criteria for diagnosing cachexia according to International Consensus is appendicular muscle mass index

Table 4 Diagnosis of cancer cachexia ${ }^{45}$

\begin{tabular}{|l|l|}
\hline Test & Finding \\
\hline Clinical & $\begin{array}{l}\text { Unintentional weight loss ( }>5 \% \\
\text { during preceding 6 months) }\end{array}$ \\
\hline Body weight & $\begin{array}{l}\text { Decreases biceps, quadriceps, } \\
\text { muscle mass }\end{array}$ \\
\hline Skeletal muscle mass & $\begin{array}{l}\text { Anorexia and/or decreased } \\
\text { food intake }\end{array}$ \\
\hline Food intake recall or diary & Increased \\
\hline Fatigue & Usually impaired \\
\hline Range of motion & Decreased scores \\
\hline Quality of life surveys & Decreased scores \\
\hline Karnofsky's Performance Scale & $\begin{array}{l}\text { Increased (acute-phase } \\
\text { response) }\end{array}$ \\
\hline Serum & $\begin{array}{l}\text { Increased (acute-phase } \\
\text { response) }\end{array}$ \\
\hline Serum C-reactive protein & Decreased (anemia) \\
\hline Serum fibrinogen & Decreased \\
\hline Serum hematocrit & \\
\hline Serum albumin &
\end{tabular}

that consistent with sarcopenia. Because of this, a physical examination has to be performed to evaluate skeletal muscle wasting and loss of body fat. The most important muscles for such an assessment are the gastrocnemius, vastus lateralis, rectus abdominus, and biceps because these type-II fast-twitch muscles are most commonly affected in cancer cachexia. ${ }^{45}$

Recently, bioelectrical impedance analysis (BIA), ${ }^{48}$ computed tomography (CT) imaging analysis, ${ }^{49}$ and dual-energy X-ray absorptiometry (DXA) ${ }^{50}$ has been introduced as tool to evaluate body composition (-Table 5). Bioelectric impedance analysis can also be used to measure body composition based on the electrical properties of tissues so it can estimate body fat percentage, fat mass, fat-free mass, and total body water with the help of predictive equations. BIA, unfortunately, has been reported not to be as reliable as DXA for assessing body composition in cancer patients $\mathrm{s}^{51}$; however, BIA can be used to calculate the phase angle which has been reported to predict poor survival in cancer patients. ${ }^{52}$

Both DXA and CT imaging both have high precision and specificity for discriminating individual tissue components and are the gold standard for body composition evaluation. DXA uses alternating high-energy and low-energy X-rays to analyze the differences between bone and soft tissue attenuating at different X-ray levels. ${ }^{50}$ It measure predominantly appendicular muscle. DXA has some limitations including inability to differentiate subsets of adipose tissue into intramuscular, visceral, and subcutaneous and lean body mass into muscle, organ, and tumor, as well as overestimation of lean body mass in settings when changes of $>5 \%$ hydration status of cancer patients. ${ }^{50}$

CT is often used over time to monitor cancer and can be taken advantage of to serve as an assessment tool for body composition. CT imaging can discriminate between adipose tissue, bone, organs, and muscle including degree of fatty infiltration by Hounsfield's units based on tissue-specific attenuation values using software programs including SliceOmatic (TomoVision, Magog, Canada), FatSeg, OsiriX, and ImageJ. ${ }^{53}$ This method measures body composition through the measurement of muscle tissue located on the level of L3 since it strongly correlates with total body skeletal muscle area ${ }^{54,55}$ Limitations of CT imaging include exposure to radiation which can be minimized if CT scans used for standard of care in cancer staging are utilized.

\section{Assessment of Quality of Life and Anorexia}

Assessing QOL is critical endpoint in cancer patients with cachexia. The functional assessment of anorexia-cachexia

Table 5 Measurement of cachexia parameters ${ }^{49-51}$

\begin{tabular}{|l|l|l|l|}
\hline Measurement & \multirow{2}{*}{ Tools } & \multicolumn{2}{|c|}{ Cut-off value $\left(\mathrm{kg} / \mathrm{m}^{2}\right)$} \\
\cline { 3 - 4 } & & Men & Women \\
\hline \multirow{2}{*}{ Appendicular skeletal muscle mass index } & Bioimpedance analysis & $<7$ & $<5.7$ \\
\cline { 2 - 4 } & Dual energy X-ray absorptiometry & $<7$ & $<5.4$ \\
\hline Lumbar skeletal muscle mass index & Computed tomography scan on L3 & $<46.12$ & $<34.18$ \\
\hline
\end{tabular}


therapy (FAACT) scale consists of the functional assessment of cancer therapy general (FACT-G) scale, and the anorexiacachexia subscale (ACS) and is a QOL scale specific for cancer patients with cachexia. ${ }^{56}$ FAACT scale includes five subscales: (1) seven items for physical well-being, (2) six items for emotional well-being, (3) seven items for social well-being, (4) seven items for functional well-being, and (5) 12 items for ACS with each item rated as a five-level scoring system (0-4 points) with a higher sum of all 39-item score equating with a better QOL. ${ }^{56}$

Another questionnaire has been developed from The European Organization for the Research and Treatment of Cancer Quality of Life Questionnaire-Core 30 (EORTCQLQ-C30) to measure QOL specifically in cancer patients with cachexia that is called EORTC QLQ-CAX24. ${ }^{57}$ It contains 24 items which consist of five multi-item scales (food aversion, eating and weight-loss worry, eating difficulties, loss of control, and physical decline) and four single items. This questionnaire can adjunct the EORTC-QLQ-C30 to achieve better measurement of QOL in cancer patients with cachexia. ${ }^{57}$

\section{Biomarkers}

When identifying and monitoring patients with cancer who have cachexia, it is important to acknowledge the potential role of biomarkers. One potential serum biomarker commonly used in clinical practice is C-reactive protein (CRP) which, when combined with additional factors of weight loss and nutritional intake, has identified patients at risk for cancer cachexia. ${ }^{58}$ Elevated CRP ( $>10 \mathrm{mg} / \mathrm{L}$ ) has been linked with weight loss and has been confirmed in numerous studies. ${ }^{59,60}$ Low serum albumin $(<35 \mathrm{~g} / \mathrm{L})$ has also been associated with weight loss. ${ }^{61}$

The modified Glasgow Prognostic Score, which is a combination of albumin and CRP, has been validated and reported to correlate with poor nutritional status and weight loss, decrease response to chemotherapy, and increased sensitivity to toxicities, and is a useful prognostic scoring tool. ${ }^{62,63}$ Ghrelin, obestatin, and leptin have also been studied as potential biomarker for cachexia. Previous study has reported raised ghrelin serum levels in cancer patients with cachexia, whereas obestatin and leptin concentrations were found to be reduced. ${ }^{64}$

\section{Treatment}

\section{Diet Modification}

Provision of adequate nutrition is a mainstay of cachexia treatment, and up to date guidelines for clinical nutrition in oncology are available. The average caloric deficit in weight-losing patients with cancer cachexia is approximately 250 to $400 \mathrm{Kcals} /$ day ${ }^{65}$ An average supplementation of 1 calorie/mL has been failed to improve the nutritional status of patients receiving chemotherapy ${ }^{47,66}$ The average protein intake in patients with cancer cachexia is approximately 0.7 to $1.0 \mathrm{~g} / \mathrm{kg}$ per day ${ }^{66}$ Food energy intake needs to increase by 300 to $400 \mathrm{kcal}$ per day and protein intake to increase by up to $50 \%$ to have an effect on anabolic resistance (recommended intake1.0-1.5 g/ $/ \mathrm{kg}$ per day). ${ }^{66}$ The use of parenteral nutrition in addition to oral nutritional support has been found to result in a short ( $6-8$ weeks) but significant $(p<0.001)$, prolongation of survival when nutritional goals were achieved according to a randomized trial. ${ }^{67}$

\section{Exercise}

Physical exercise has been suggested as a promising countermeasure for preventing cachexia. ${ }^{68}$ The rationale for the use of exercise relies on the known dramatic reduction of muscle strength and endurance during cachexia. ${ }^{68}$ Physical exercise increases insulin sensitivity, protein synthesis rate, and antioxidative enzyme activity. ${ }^{69}$ It may also lead to suppression of the inflammatory response and an enhancement of immune function. ${ }^{70}$

There is significant evidence that endurance exercise (e.g., a high number of repetitions performed over extended time periods against relatively low resistance) ameliorates cancer-related fatigue. ${ }^{71}$ Combination of resistance and aerobic muscle training has been suggested to be incorporated into cachexia treatment programs. ${ }^{71}$

\section{Pharmacologic Treatment Corticosteroids}

Corticosteroids are widely used as orexigenic agents, ${ }^{72}$ as they can exert a limited benefit in the management of cancer associated cachexia by improving appetite, caloric intake, pain control, inducing a sensation of wellbeing and reducing nausea. Prednisolone at a dose of $3 \times 5 \mathrm{mg}$ and dexamethasone 3 to $6 \mathrm{mg}$ daily has been shown an appetite enhancement respect toplacebo. ${ }^{73}$ Methylprednisolone given intravenously at a dose of $125 \mathrm{mg}$ daily will ameliorate QOL. ${ }^{74}$ Nevertheless, these positive effects are of short duration and do not lead to an increase in body weight. ${ }^{75}$

\section{Progestogens}

Megestrol acetate (MA) and medroxyprogesterone acetate (MPA) are synthetic, orally active progestational agents. In several randomized controlled studies, these com pounds have been found to improve appetite, caloric intake, and nutritional status in patients with nonhormone responsive tumors and cancer anorexia-cachexia syndrome. ${ }^{76-78}$ MA has demonstrated a dose-related beneficial effect, in a dose range from 160 to $1,600 \mathrm{mg} /$ day on appetite, caloric intake, body weight gain (mainly fat), and sensation of wellbeing (with an optimal dosage of $800 \mathrm{mg}$ daily). ${ }^{77,78}$ It is recommended that a patient is started on the lowest dosage (i.e., $160 \mathrm{mg} /$ day) and that the dose is up-titrated according to clinical response. ${ }^{78,79}$ MPA has similarly been shown to increase appetite and food intake with a stabilization of body weight at a dose of $1,000 \mathrm{mg}$ (i.e., $500 \mathrm{mg}$ twice daily). ${ }^{78,79}$ Although the drug is safe at doses of 500 to $4,000 \mathrm{mg}$ daily, side effects have been shown to increase above oral doses of 1,000 mg. ${ }^{76}$

\section{Cannabinoids}

Tetrahydrocannabinol (THC) and its derivatives are synthetic pharmaceuticals able to activate cannabinoid receptors and in particular, the CB1 receptors localized in the hypothalamus and the limbic system. Cannabinoids have been investigated 
in patients with cancer for antiemetic and appetite-stimulant activity. ${ }^{80}$ Dronabinol is the synthetic oral form of tetrahydrocannabinol (THC), which is the active agent in marijuana thought to be responsible for these effects. The mechanism of action of dronabinol is not completely understood, but its activity is likely mediated by cannabinoid receptor-related processes. ${ }^{81}$

\section{Ghrelin}

Ghrelin is a 28-amino acid peptide hormone mostly produced in the stomach but also in other gastrointestinal tissues. It induces the release of growth hormone from the pituitary gland, stimulates food intake ${ }^{82}$ and also suppress the production of proinflammatory cytokines. ${ }^{83}$ In 2007, DeBoer et al observed a significant increase in food intake and weight gain after administration of human ghrelin or a synthetic ghrelin analogous BIM-28131 in a rat model of cancer associated cachexia. ${ }^{84}$ At present, a phase-II randomized, placebo-controlled, double-blind study, using an oral ghrelin mimetic, demonstrated an improvement in lean body mass, total body mass, and hand-grip strength in cachectic cancer patients. ${ }^{85}$ Several clinical trials with ghrelin are currently on going.

\section{Thalidomide}

TNF- $\alpha$, IL-6, and IFN- $\gamma$ have all been implicated in the pathogenesis of cachexia. Thalidomide (a-N-phthalimidoglutarimide) has complex immune-modulatory and antiinflammatory properties. Thalidomide has been shown to counter TNF $\alpha$ and IL-6 production..$^{86,87}$ One randomized placebo-controlled trial in patients with cancer cachexia showed that the drug was well-tolerated and effective at attenuating loss of weight and lean body mass in patients with advanced pancreatic cancer. ${ }^{88}$

\section{Omega-3 Fatty Acids}

Eicosapentaenoic acid (EPA) is one of several omega-3 polyunsaturated fatty acids found abundantly in fish oil. Polyunsaturated fatty acids have been proposed to reduce cachexia-associated tissue wasting, ${ }^{89}$ as well as tumor growth. ${ }^{8990}$ EPA downregulates the production of proinflammatory cytokines in both healthy individuals and patients with cancer. Furthermore, the effects of proteolysis inducing factor, a cachectic factor produced by cancer, are also inhibited by EPA.

\section{Conclusion}

Patients with cancer are the population at risk to develop cachexia before and after chemotherapy. The loss of weight that happens during chemotherapy will make a poor prognosis. Cachexia can worse chemotherapy toxicity. Cachexia diagnosis needs evaluation of body weight, food intake, and body composition. Dietary modification and physical exercise is the best strategy for cachexia in cancer patients. Some medications that alter appetite and inflammatory cytokines can be added to improve QOL.

\section{Conflict of Interest}

None declared.

\section{References}

1 DeWys WD. Pathophysiology of cancer cachexia: current understanding and areas for future research. Cancer Res 1982;42(2(suppl) :721s-726s

2 Fearon K, Arends J, Baracos V. Understanding the mechanisms and treatment options in cancer cachexia. Nat Rev Clin Oncol 2013;10(2):90-99

3 Muscaritoli M, Bossola M, Aversa Z. Bellantone R, Rossi Fanelli F. Prevention and treatment of cancer cachexia: new insights into an old problem. Eur J Cancer 2006;42(1):31-41

4 Dewys WD, Begg C, Lavin PT, et al; Eastern Cooperative Oncology Group. Prognostic effect of weight loss prior to chemotherapy in cancer patients. Am J Med 1980;69(4):491-497

5 Mercadante S, Valle A, Porzio G, Aielli F, Adile C, Casuccio A; Home Care-Italy Group. Prognostic factors of survival in patients with advanced cancer admitted to home care. J Pain Symptom Manage 2013;45(1):56-62

6 Gordon JN, Green SR, Goggin PM. Cancer cachexia. QJM 2005;98(11):779-788

7 Hopkinson JB, Wright DN, McDonald JW, Corner JL. The prevalence of concern about weight loss and change in eating habits in people with advanced cancer. J Pain Symptom Manage 2006;32(4):322-331

8 Muscaritoli M, Anker SD, Argilés J, et al. Consensus definition of sarcopenia, cachexia and pre-cachexia: joint document elaborated by Special Interest Groups (SIG) "cachexia-anorexia in chronic wasting diseases" and "nutrition in geriatrics" Clin Nutr 2010;29(2):154-159

9 Katz AM, Katz PB. Diseases of the heart in the works of Hippocrates. Br Heart J 1962;24:257-264

10 Doehner W, Anker SD. Cardiac cachexia in early literature: a review of research prior to Medline. Int J Cardiol 2002;85(1):7-14

11 Evans WJ, Morley JE, Argilés J, et al. Cachexia: a new definition. Clin Nutr 2008;27(6):793-799

12 Fearon K, Strasser F, Anker SD, et al. Definition and classification of cancer cachexia: an international consensus. Lancet Oncol 2011;12(5):489-495

13 Vigano A, Del Fabbro E, Bruera E, Borod M. The cachexia clinic: from staging to managing nutritional and functional problems in advanced cancer patients. Crit Rev Oncog 2012;17(3):293-303

14 Argilés JM, Betancourt A, Guàrdia-Olmos J, et al. Validation of the CAchexia SCOre (CASCO). Staging cancer patients: the use of miniCASCO as a simplified tool. Front Physiol 2017;8:92

15 Fredrix EW, Wouters EF, Soeters PB, et al. Resting energy expenditure in patients with non-small cell lung cancer Cancer 1991;68(7):1616-1621

16 Peacock JL, Inculet RI, Corsey R, et al. Resting energy expenditure and body cell mass alterations in noncachectic patients with sarcomas. Surgery 1987;102(3):465-472

17 Haslett PA. Anticytokine approaches to the treatment of anorexia and cachexia. Semin Oncol 1998;25(2(suppl 6): 53-57

18 Tisdale MJ. Biology of cachexia. J Natl Cancer Inst 1997;89(23): 1763-1773

19 Moldawer LL, Copeland EM III. Proinflammatory cytokines, nutritional support, and the cachexia syndrome: interactions and therapeutic options. Cancer 1997;79(9):1828-1839

20 Guttridge DC, Mayo MW, Madrid LV. Wang CY, Baldwin AS Jr. NF-kappaB-induced loss of MyoD messenger RNA: possible role in muscle decay and cachexia. Science 2000;289(5488):2363-2366 
21 Acharyya S, Ladner KJ, Nelsen LL, et al. Cancer cachexia is regulated by selective targeting of skeletal muscle gene products. J Clin Invest 2004;114(3):370-378

22 Khan S, Tisdale MJ. Catabolism of adipose tissue by a tumourproduced lipid-mobilising factor. Int J Cancer 1999;80(3): 444-447

23 Islam-Ali B, Khan S, Price SA, Tisdale MJ. Modulation of adipocyte G-protein expression in cancer cachexia by a lipid-mobilizing factor (LMF) Br J Cancer 2001;85(5):758-763

24 Baracos VE, DeVivo C, Hoyle DH, Goldberg AL. Activation of the ATP-ubiquitin-proteasome pathway in skeletal muscle of cachectic rats bearing a hepatoma. Am J Physiol 1995;268(5, Pt 1) :E996-E1006

25 Zhang L, Tang H, Kou Y, et al. MG132-mediated inhibition of the ubiquitin-proteasome pathway ameliorates cancer cachexia. J Cancer Res Clin Oncol 2013;139(7):1105-1115

26 Friedman JM, Halaas JL. Leptin and the regulation of body weight in mammals. Nature 1998;395(6704) :763-770

27 Flier JS, Maratos-Flier E. Obesity and the hypothalamus: novel peptides for new pathways. Cell 1998;92(4):437-440

28 Inui A. Cancer anorexia-cachexia syndrome: are neuropeptides the key? Cancer Res 1999;59(18):4493-4501

29 Yakabi K, Sadakane C, Noguchi M, et al. Reduced ghrelin secretion in the hypothalamus of rats due to cisplatin-induced anorexia. Endocrinology 2010;151(8):3773-3782

30 Steinbach S, Hummel T, Böhner C, et al. Qualitative and quantitative assessment of taste and smell changes in patients undergoing chemotherapy for breast cancer or gynecologic malignancies. J Clin Oncol 2009;27(11):1899-1905

31 Elkina Y, von Haehling S, Anker SD, Springer J. The role of myostatin in muscle wasting: an overview. J Cachexia Sarcopenia Muscle 2011;2(3):143-151

32 Zimmers TA, Davies MV, Koniaris LG, et al. Induction of cachexia in mice by systemically administered myostatin. Science 2002;296(5572):1486-1488

33 Morissette MR, Cook SA, Buranasombati C, Rosenberg MA, Rosenzweig A. Myostatin inhibits IGF-I-induced myotube hypertrophy through Akt. AmJ Physiol Cell Physiol2009;297(5): C1124-C1132

34 Costelli P, Muscaritoli M, Bossola M, et al. IGF-1 is downregulated in experimental cancer cachexia. Am J Physiol Regul Integr Comp Physiol 2006;291(3):R674-R683

35 Prado CM, Baracos VE, McCargar LJ, et al. Body composition as an independent determinant of 5-fluorouracil-based chemotherapy toxicity. Clin Cancer Res 2007;13(11):3264-3268

36 Barret M, Antoun S, Dalban C, et al. Sarcopenia is linked to treatment toxicity in patients with metastatic colorectal cancer. Nutr Cancer 2014;66(4):583-589

37 Bozzetti F. Forcing the vicious circle: sarcopenia increases toxicity, decreases response to chemotherapy and worsens with chemotherapy. Ann Oncol 2017;28(9):2107-2118

38 Arends J, Bachmann P, Baracos V, et al. ESPEN guidelines on nutrition in cancer patients. Clin Nutr 2017;36(1):11-48

39 Blum D, Strasser F. Cachexia assessment tools. Curr Opin Support Palliat Care 2011;5(4):350-355

40 Martin L, Watanabe S, Fainsinger R, et al. Prognostic factors in patients with advanced cancer: use of the patient-generated subjective global assessment in survival prediction. J Clin Oncol 2010;28(28):4376-4383

41 Gioulbasanis I, Georgoulias P, Vlachostergios PJ, et al. Mini Nutritional Assessment (MNA) and biochemical markers of cachexia in metastatic lung cancer patients: interrelations and associations with prognosis. Lung Cancer 2011;74(3):516-520

42 Neelemaat F, Meijers J, Kruizenga H, van Ballegooijen H, van Bokhorst-de van der Schueren M. Comparison of five malnutrition screening tools in one hospital inpatient sample. J Clin Nurs 2011;20(15-16):2144-2152
43 Boléo-Tomé C, Chaves M, Monteiro-Grillo I, Camilo M, Ravasco P. Teaching nutrition integration: MUST screening in cancer. Oncologist 2011;16(2):239-245

44 Kondrup J, Allison SP, Elia M, Vellas B, Plauth M; Educational and Clinical Practice Committee, European Society of Parenteral and Enteral Nutrition (ESPEN). ESPEN guidelines for nutrition screening 2002. Clin Nutr 2003;22(4):415-421

45 Mondello P, Mian M, Aloisi C, Famà F, Mondello S, Pitini V. Cancer cachexia syndrome: pathogenesis, diagnosis, and new therapeutic options. Nutr Cancer 2015;67(1):12-26

46 Couch M, Lai V, Cannon T, et al. Cancer cachexia syndrome in head and neck cancer patients: part I. Diagnosis, impact on quality of life and survival, and treatment. Head Neck 2007;29(4):401-411

47 Agustsson T, Rydén M, Hoffstedt J, et al. Mechanism of increased lipolysis in cancer cachexia. Cancer Res 2007;67(11): 5531-5537

48 Chen LK, Liu LK, Woo J, et al. Sarcopenia in Asia: consensus report of the Asian Working Group for Sarcopenia. J Am Med Dir Assoc 2014;15(2):95-101

49 Jo MH, Lim TS, Jeon MY, et al. Predictors of discordance in the assessment of skeletal muscle mass between computed tomography and bioimpedance analysis. J Clin Med 2019;8(3):322

50 Shafiee G, Ostovar A, Heshmat R, et al. Appendicular skeletal muscle mass reference values and the peak muscle mass to identify sarcopenia among Iranian healthy population. Int J Prev Med 2018;9:25

51 Trutschnigg B, Kilgour RD, Reinglas J, et al. Precision and reliability of strength (Jamar vs. Biodex handgrip) and body composition (dual-energy X-ray absorptiometry vs. bioimpedance analysis) measurements in advanced cancer patients. Appl Physiol Nutr Metab 2008;33(6):1232-1239

52 Hui D, Bansal S, Morgado M, Dev R, Chisholm G, Bruera E. Phase angle for prognostication of survival in patients with advanced cancer: preliminary findings. Cancer 2014;120(14):2207-2214

53 van Vugt JLA, Levolger S, Gharbharan A, et al. A comparative study of software programmes for cross-sectional skeletal muscle and adipose tissue measurements on abdominal computed tomography scans of rectal cancer patients. J Cachexia Sarcopenia Muscle 2017;8(2):285-297

54 Baracos VE, Reiman T, Mourtzakis M, Gioulbasanis I, Antoun S. Body composition in patients with non-small cell lung cancer: a contemporary view of cancer cachexia with the use of computed tomography image analysis. Am J Clin Nutr 2010;91(4):1133S-1137S

55 Mourtzakis M, Prado CM, Lieffers JR, Reiman T, McCargar LJ, Baracos VE. A practical and precise approach to quantification of body composition in cancer patients using computed tomography images acquired during routine care. Appl Physiol Nutr Metab 2008;33(5):997-1006

56 Blauwhoff-Buskermolen S, Ruijgrok C, Ostelo RW, et al. The assessment of anorexia in patients with cancer: cut-off values for the FAACT-A/CS and the VAS for appetite. Support Care Cancer 2016;24(2):661-666

57 Wheelwright SJ, Hopkinson JB, Darlington A-S, et al; EORTC Quality of Life Group. Development of the EORTC QLQ-CAX24, A Questionnaire for Cancer Patients With Cachexia. J Pain Symptom Manage 2017;53(2):232-242

58 Tan BH, Deans DA, Skipworth RJ, Ross JA, Fearon KC. Biomarkers for cancer cachexia: is there also a genetic component to cachexia? Support Care Cancer 2008;16(3):229-234

59 Punzi T, Fabris A, Morucci G, et al. C-reactive protein levels and vitamin d receptor polymorphisms as markers in predicting cachectic syndrome in cancer patients. Mol Diagn Ther 2012;16(2):115-124

60 Krzystek-Korpacka M, Matusiewicz M, Diakowska D, et al. Acute-phase response proteins are related to cachexia and 
accelerated angiogenesis in gastroesophageal cancers. Clin Chem Lab Med 2008;46(3):359-364

61 Gabay C, Kushner I, Kushner I. Acute-phase proteins and other systemic responses to inflammation. $\mathrm{N}$ Engl J Med 1999;340(6):448-454

62 Gioulbasanis I, Pallis A, Vlachostergios PJ, et al. The Glasgow Prognostic Score (GPS) predicts toxicity and efficacy in platinum-based treated patients with metastatic lung cancer. Lung Cancer 2012;77(2):383-388

63 Giannousi Z, Gioulbasanis I, Pallis AG, et al. Nutritional status, acute phase response and depression in metastatic lung cancer patients: correlations and association prognosis. Support Care Cancer 2012;20(8):1823-1829

64 Mantovani G, Macciò A, Mura L, et al. Serum levels of leptin and proinflammatory cytokines in patients with advanced-stage cancer at different sites.J Mol Med (Berl) 2000;78(10):554-561

65 Kumar NB, Kazi A, Smith T, et al. Cancer cachexia: traditional therapies and novel molecular mechanism-based approaches to treatment. Curr Treat Options Oncol 2010;11(3-4):107-117

66 Fearon KCH, Von Meyenfeldt MF, Moses AGW, et al. Effect of a protein and energy dense $\mathrm{N}-3$ fatty acid enriched oral supplement on loss of weight and lean tissue in cancer cachexia: a randomised double blind trial. Gut 2003;52(10):1479-1486

67 Lundholm K, Daneryd P, Bosaeus I, Körner U, Lindholm E. Palliative nutritional intervention in addition to cyclooxygenase and erythropoietin treatment for patients with malignant disease: Effects on survival, metabolism, and function. Cancer 2004;100(9):1967-1977

68 Lenk K, Schuler G, Adams V. Skeletal muscle wasting in cachexia and sarcopenia: molecular pathophysiology and impact of exercise training. J Cachexia Sarcopenia Muscle 2010;1(1):9-21

69 Radbruch L, Elsner F, Trottenberg P, Strasser F, Fearon K. Clinical practice guidelines on cancer cachexia in advanced cancer patients. Available at: http://www.cancercachexia. com/literature-watch/43_clinical-practice-guidelines-on-cancer-cachexia-in-advanced-cancer. Accessed May 28, 2020

70 Ardies CM. Exercise, cachexia, and cancer therapy: a molecular rationale. Nutr Cancer 2002;42(2):143-157

71 Argilés JM, Busquets S, López-Soriano FJ, Costelli P, Penna F. Are there any benefits of exercise training in cancer cachexia? J Cachexia Sarcopenia Muscle 2012;3(2):73-76

72 Shih A, Jackson KC II. Role of corticosteroids in palliative care. J Pain Palliat Care Pharmacother 2007;21(4):69-76

73 Barber MD, Ross JA, Fearon KC. Cancer cachexia. Surg Oncol 1999;8(3):133-141

74 Popiela T, Lucchi R, Giongo F; The Methylprednisolone Female Preterminal Cancer Study Group. Methylprednisolone as palliative therapy for female terminal cancer patients. Eur J Cancer Clin Oncol 1989;25(12):1823-1829
75 Melstrom LG, Melstrom KA Jr, Ding XZ, Adrian TE. Mechanisms of skeletal muscle degradation and its therapy in cancer cachexia. Histol Histopathol 2007;22(7):805-814

76 Nelson KA. The cancer anorexia-cachexia syndrome. Semin Oncol 2000;27(1):64-68

77 Loprinzi CL, Ellison NM, Schaid DJ, et al. Controlled trial of megestrol acetate for the treatment of cancer anorexia and cachexia. J Natl Cancer Inst 1990;82(13):1127-1132

78 Loprinzi CL, Michalak JC, Schaid DJ, et al. Phase III evaluation of four doses of megestrol acetate as therapy for patients with cancer anorexia and/or cachexia. J Clin Oncol 1993;11(4):762-767

79 Mantovani G, Macciò A, Massa E, Madeddu C. Managing cancer-related anorexia/cachexia. Drugs 2001;61(4):499-514

80 Abrams DI, Guzman M. Cannabis in cancer care. Clin Pharmacol Ther 2015;97(6):575-586

81 Birdsall SM, Birdsall TC, Tims LA. The use of medical marijuana in cancer. Curr Oncol Rep 2016;18(7):40

82 Fanzani A, Conraads VM, Penna F, Martinet W. Molecular and cellular mechanisms of skeletal muscle atrophy: an update. J Cachexia Sarcopenia Muscle 2012;3(3):163-179

83 Akamizu T, Kangawa K. Ghrelin for cachexia. J Cachexia Sarcopenia Muscle 2010;1(2):169-176

84 DeBoer MD, Zhu XX, Levasseur P, et al. Ghrelin treatment causes increased food intake and retention of lean body mass in a rat model of cancer cachexia. Endocrinology 2007;148(6):3004-3012

85 Garcia J, Boccia R, Graham C. A phase II randomized, placebo-controlled, double-blind study of the efficacy and safety of RC-1291 (RC) for the treatment of cancer cachexia. J Clin Oncol 2007;25:9133

86 Gordon JN, Trebble TM, Ellis RD, et al. Thalidomide in the treatment of cancer cachexia: a randomised placebo controlled trial. Gut 2005;54:447-448

87 Reid J, Mills M, Cantwell M, Cardwell CR, Murray LJ, Donnelly M. Thalidomide for managing cancer cachexia. Cochrane Database Syst Rev 2012;4(4):CD008664

88 Tisdale MJ. Mechanism of lipid mobilization associated with cancer cachexia: interaction between the polyunsaturated fatty acid, eicosapentaenoic acid, and inhibitory guanine nucleotide-regulatory protein. Prostaglandins Leukot Essent Fatty Acids 1993;48(1):105-109

89 Anti M, Marra G, Armelao F, et al. Effect of omega-3 fatty acids on rectal mucosal cell proliferation in subjects at risk for colon cancer. Gastroenterology 1992;103(3):883-891

90 Rose DP, Connolly JM. Effects of dietary omega-3 fatty acids on human breast cancer growth and metastases in nude mice. J Natl Cancer Inst 1993;85(21):1743-1747 